\title{
Corrigendum: Chemical trapping and crystal structure of a catalytic tRNA guanine transglycosylase covalent intermediate
}

Wei Xie, Xianjun Liu \& Raven H Huang

Nat. Struct. Biol. 10, 781-788 (2003).

Two mistakes are found in the final version of this manuscript. The first is on page 784 (second column, line 19 from the bottom); the correct sentence should read: “. .. in which the base U33 forms hydrogen bonds with the main chain amide and carbonyl groups of Gly263...." The second is on page 786, where Figure 6 was incorrectly referred to six times in the Results section. The correct figure described on this page is

Figure 7. We apologize for any inconvenience this may have caused.

\section{Erratum: Cooperative organization in a macromolecular complex}

Markus A Seeliger, Sadie E Breward, Assaf Friedler, Oliver Schon \& Laura S Itzhaki

Nat. Struct. Biol. 10, 718-724 (2003).

A mistake was introduced when the electronic document of this manuscript was being converted for production. The mistake is in the peptide sequence corresponding to the 19 residues at the $\mathrm{C}$ terminus of $\mathrm{p}^{\mathrm{Kip} 1}$ (page 723 , second column, line 2). The correct sequence should be: NAGSVEQ(pT)PKKPGLRRRQT. We apologize for any inconvenience this may have caused.

\section{Erratum: A fine balance for life and death decisions}

Barbara A Schreader \& John R Nambu

Nat. Struct. Mol. Biol. 11, 386-388 (2004).

During production an incorrect version of Figure 1 was placed in the final version of this manuscript. The correct figure is reprinted here. We apologize for any inconvenience this may have caused.

\section{a}

Cell survival

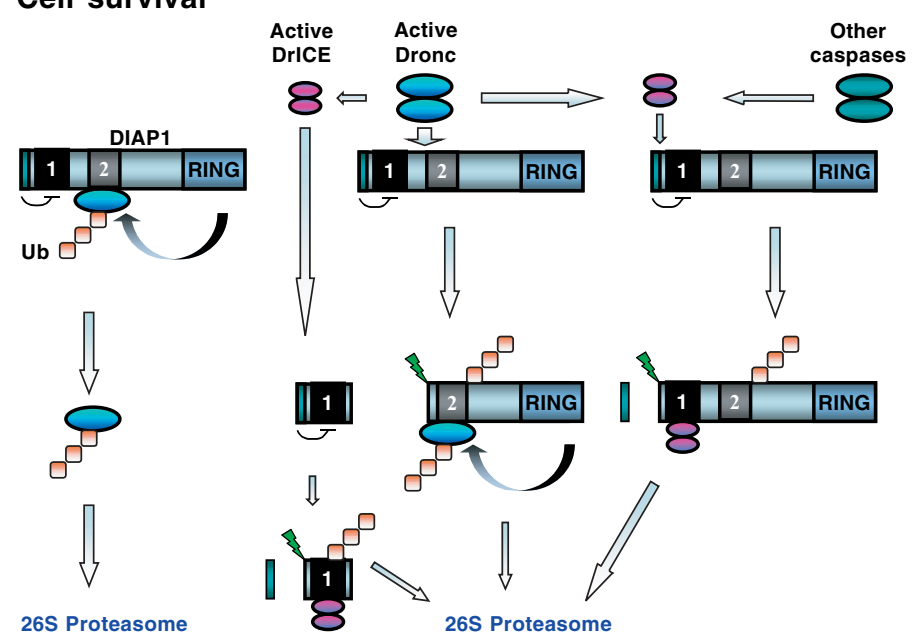

b

Cell death
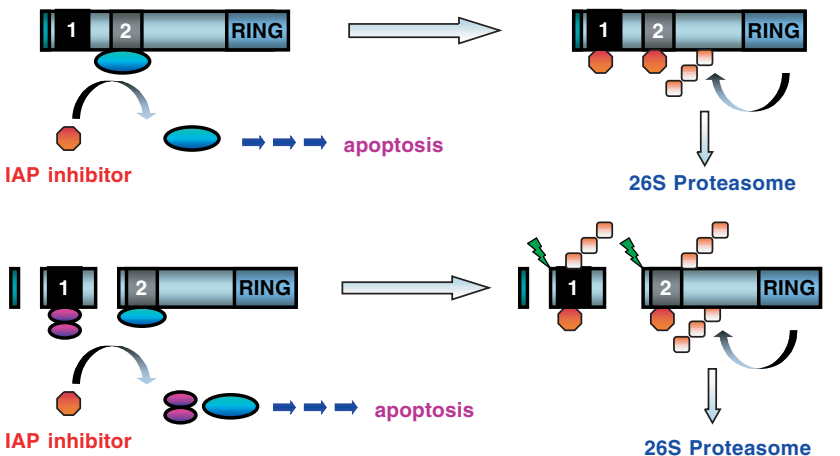